\title{
COMPARISON OF CLASSIC AND DERIVATIVE UV SPECTROPHOTOMETRIC METHODS FOR DETERMINATION OF DEXTROMETHORPHANI HYDROBROMIDUM
}

\author{
Drozd, $J$.
}

Medical University of Lublin, Faculty of Pharmacy, Department Medicinal Chemistry

\begin{abstract}
A method for the fast determination of dextromethorphani hydrobromidum in pharmaceutical preparations by classic spectrophotometry - zero and first-, second- and third-order derivative spectrophotometry, using "peak - peak" $(\mathrm{P}-\mathrm{P})$ and "peak - zero" $(\mathrm{P}-\mathrm{O})$ measurements has been performed. The calibration curves are linear within the concentration range of $1.0-25.0 \mu \mathrm{g} \mathrm{ml}^{-1}$ for dextromethorphani hydrobromidum. The procedure is simple, rapid and the results are reliable.
\end{abstract}

Keywords: Dextromethorphani hydrobromidum - classic spectrophotometry - derivative spectrophotometry

\section{INTRODUCTION}

Dextromethorphan $(D X M)((+)-3$-methoxy-17-methyl-9 $\alpha, 13 \alpha, 14 \alpha$-morphinan) (Figure $1)$, is the dextrorotatory enantiomer of the methyl ether of levorphanol, a codeine analogue and opioid analgesic, used in the form of the base or as the monohydrated hydrobromide salt. Dextromethorphan is a cough suppressant, approved by the Food and Drug Administration (FDA), which is found in many over-the-counter (OTC) cough and cold remedies. It is generally safe when taken at recommended doses. The average dosage necessary for effective antitussive therapy is between $10 \mathrm{mg}$ and $45 \mathrm{mg}$, depending on the individual (1/6 to $1 / 3$ ounce of medication, containing $15 \mathrm{mg}$ to $30 \mathrm{mg}$ $D X M$ ). When taken in large amounts (e.g. 100 milligrams or more), though, $D X M$ can produce hallucinations and a "high" similar to psychotropic drugs, such as phencyclidine $(P C P)$ and ketamine (Brenner \& Stevens, 2006, Brunton et al., 2005). Dangerous side effects may include blurred vision, loss of physical coordination, abdominal pain, and rapid heart beat. Side effects may be worsened if the ingested product also contains other pharmaceutical ingredients, such as acetaminophen, pseudoephedrine, antihistamines, or expectorants, which are commonly found in cough and cold medicines. A combination of $D X M$ and quinidine has been shown to alleviate symptoms of easy laughing and crying (pseudobulbar affect) in patients 
with amyotrophic lateral sclerosis and multiple sclerosis. $D X M$ is also being investigated as a possible treatment for neuropathic pain and pain associated with fibromyalgia (Brenner \& Stevens, 2006, Brunton et al., 2005).

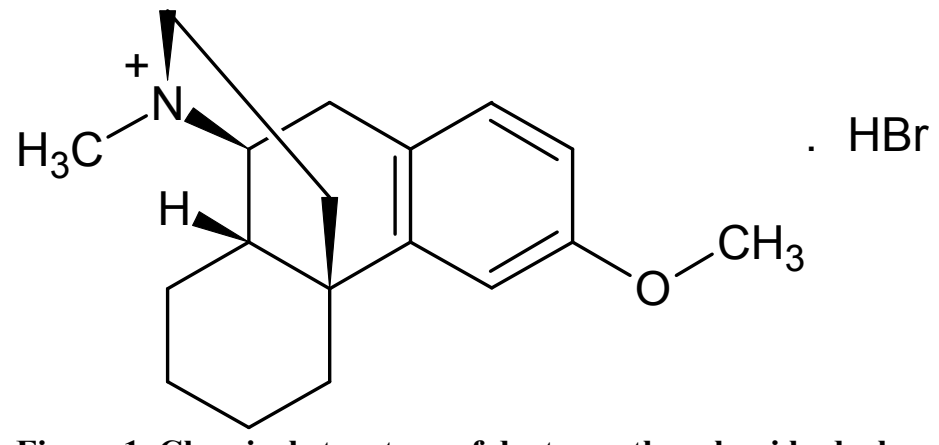

Figure 1. Chemical structure of dextromethorphani hydrobromidum

Dextromethorphan is rapidly absorbed from the gastrointestinal tract and converted (Odemethylation) into the less active metabolite, dextrorphan (3-hydroxy derivative) in the liver by the cytochrome P450 enzyme CYP2D6. Approximately 1 in 10 of the population has little or no CYP2D6 enzyme activity leading to long lived high drug levels (Brenner \&Stevens, 2006, Brunton et al., 2005).

Due to the medical importance of $D X M$ and its widespread use, several analytical methods have been employed for the determination of $D X M$ in the bulk and in the dosage forms and in biological fluids. Most of those analytical methods imply chromatographic techniques, such as HLPC (Galli \& Barbas, 2004, Lin et al., 2007, Louhaichi et al., 2009, Santagati et al., 2005), HPLC-MS/MS (Lou et al., 2010, Zhang et al., 2010), GC-MS (Bagheri et al., 2005), and capillary electrophoresis (Dong et al., 2005, Yang et al., 2008). For the quantification of $D X M$, literature recommended either electrooxidation on a carbon nanotube--carbon microparticle liquid composite (Heli et al., 2010), or FIA with potentiometric detection (Khaled et al., 2010) and potentiometric membrane sensors (El- Naby, 2008). However, many of these methods require several time-consuming manipulation steps, sophisticated instruments and special training. On the other hand, the increasing trend of $D X M$ abuse over recent years has been created and used for highly selective and precise analytical methodologies. This practice is suitable for it is not very expensive and is easy on use.

Over the last decade, no publications were reported on the determination of dextromethorphani hydrobromidum by UV derivative spectrophotometry. This method still offers an alternative approach to the enhancement of sensitivity and specificity of the drug analysis (Sánchez \& Bosch, 2008). This paper described two simple, rapid, accurate and economical 'UV spectrophotometry' and first-, second- and third-order derivative UV spectrophotometry methods determining dextromethorphani hydrobromidum in base, in pharmaceutical preparation. Consequently, these methods are a suitable assay to indicate stability. 


\section{EXPERIMENTAL PART}

\section{Reagents and apparatus}

Dextromethorphani hydrobromidum $(D X M H B r)$ - substance was obtained from Sanofi - Aventis Rzeszów, ACODIN - tablets (15 mg of dextromethorphani hydrobromidum) were obtained from a local drug store. A CECIL CE 6600 DOUBLE BEAM UV-VIS spectrophotometer, with capability of applying the derivative mode, was used. The optimized operating conditions for recording the first-, second- and third-order derivative spectra were: scan speed $5.0 \mathrm{~nm} / \mathrm{s}$, time response $2 \mathrm{~s}$ and bandwidth $2.0 \mathrm{~nm}$. All measurements were carried out in a $1 \mathrm{~cm}$ matched quartz cuvettes. Water was purified by double distillation.

\section{Preparation of the calibration curve for $D X M$}

The stock solution, $1.0 \mathrm{mg} \mathrm{ml}^{-1}$ of $D X M H B r$, was freshly prepared by dissolving appropriate amounts of substance in ethanol. Working standard solutions of $D X M \mathrm{HBr}$ in ethanol, containing increasing concentrations of $D X M \mathrm{HBr}$ ranging from 1.0 to 25.0 $\mu \mathrm{g} \mathrm{ml}^{-1}$, were prepared daily from the stock solution. The zero-, first-, second- and thirdorder derivative spectra of these solutions were recorded over the wavelength range 240 $-320 \mathrm{~nm}$ against ethanol as blank, and the amplitudes of the maximum and minimum were measured.

\section{Determination of $D X M \mathrm{HBr}$ in Acodin tablets}

Ten tablets of Acodin (each tablet weighing $-0.1026 \mathrm{~g}$ on average, containing $15 \mathrm{mg}$ of $D X M H B r$ ) were weighed and powdered. An accurately weighed portion of the powder (corresponding to $10 \mathrm{mg}$ active substance) was transferred into a $10 \mathrm{ml}$ volumetric flask containing approx. $7 \mathrm{ml}$ ethanol. The mixtures were extracted by shaking the flask for $30 \mathrm{~min}$, the volumes were then brought to $10 \mathrm{ml}$ with ethanol, and the solutions were mixed well and filtered. After filtration the extract of $1.0 \mathrm{ml}$ volume was transferred into $10 \mathrm{ml}$ flask and made with ethanol up to $10.0 \mathrm{ml}$. The concentration of the drug examined in the sample solution was found from the corresponding calibration curve. The first-, second- and third-order derivative spectra of these solutions were recorded against ethanol as blank, and amplitudes of the maximum and minimum were recorded. The procedure was repeated six times.

\section{RESULTS AND DISCUSSION}

The influence of the operating parameters, such as slit width, $\Delta \lambda$ - interpoint distance, scan rate and response time on the shape of derivative spectra of dextromethorphani hydrobromidum were studied. Under the optimum conditions regularly shaped spectral peaks free from the noise were obtained. Dextromethorphan is a base compound due to presence of the basic nitrogen atom in its molecule. It is a characteristic of free solubility in acidic aqueous media and in ethanol. In base solution (e.g. $0.1 \mathrm{~mol} \mathrm{l}^{-1}$ sodium hydroxide) $D X M$ was precipitated.

In preliminary research, the influence of $0.1 \mathrm{~mol} \mathrm{l}^{-1} \mathrm{HCl}$, methanol, ethanol and water purified by double distillation, on the absorption spectra of the best technique and wavelength range for the determination of this substance in pharmaceutical form, was studied. 
Table 1. Parameters linearity of the determination of $D X M H B r$ using UV spectra (A) and derivative spectra D1, D2 and D3

\begin{tabular}{|c|c|c|c|c|}
\hline Parameter & $\mathrm{A} / 280$ & D1/ 276-291 & D2/ $288-293,5$ & D3/ 291 \\
\hline $\begin{array}{l}\text { Slope a } \\
\text { Standard of error Slope } S_{a} \\
\text { Confidence interval of Slope } \\
\pm \Delta \mathrm{a}\end{array}$ & $\begin{array}{l}0.59156 \\
0.00693 \\
0.00600\end{array}$ & $\begin{array}{l}1,25867 \\
0.03505 \\
0.03072\end{array}$ & $\begin{array}{l}-0.01798 \\
0.02341 \\
0.02052\end{array}$ & $\begin{array}{l}0.01124 \\
0.00022 \\
0.00019\end{array}$ \\
\hline $\begin{array}{l}\text { Intercept } \mathrm{b} \\
\text { Standard of error of Intercept } \\
\mathrm{S}_{\mathrm{b}} \\
\text { Confidence interval } \\
\text { of Intercept } \Delta \mathrm{b} \pm\end{array}$ & $\begin{array}{l}0.00794 \\
0.01696 \\
0.01480\end{array}$ & $\begin{array}{l}0.00906 \\
0.04802 \\
0.04209\end{array}$ & $\begin{array}{l}0.00117 \\
0.00111 \\
0.00097\end{array}$ & $\begin{array}{l}0.00017 \\
0.00024 \\
0.00021\end{array}$ \\
\hline Correlation coefficient & 0.99954 & 0.99935 & 0.99943 & 0.99922 \\
\hline Quantitation Limit $\left(\mu \mathrm{g} \cdot \mathrm{ml}^{-1}\right)$ & 0.11724 & 0.27847 & 0.130165 & 0.20005 \\
\hline Limit of detection $\left(\mu \mathrm{g} \cdot \mathrm{ml}^{-1}\right)$ & 0.03869 & 0.09189 & 0.04295 & 0.06602 \\
\hline $\begin{array}{l}\text { Precision RSD \% for the } \\
\text { lowest and highest } \\
\text { concentration of DXM } \\
\text { standard solution }\end{array}$ & $\begin{array}{l}2.73 \\
0.80\end{array}$ & $\begin{array}{l}1.86 \\
0.62\end{array}$ & $\begin{array}{l}1.82 \\
0.60\end{array}$ & $\begin{array}{l}1.82 \\
0.60\end{array}$ \\
\hline
\end{tabular}

The best results for the analytical purposes were obtained with ethanol. The solution used was stable for one month. In order to determine the values of spectra derivatives, two graphical techniques - "peak- zero" and "peak to peak" - have been used. In the "peak to peak" technique, the determination was carried out by measuring the amplitude - from the maximum to the minimum of the curve. In the "baseline to peak" technique, the measurement was carried out from the maximum to the zero line or from the minimum to the zero line. Linearity: the calibration curves referring to the first-, second- and third-order derivative UV spectra were constructed by plotting the graphically measured (nm) amplitudes versus the corresponding concentrations $1.0-25 \mu \mathrm{g} \mathrm{ml}^{-1}$ of the examined drug (Figure 2). 
A

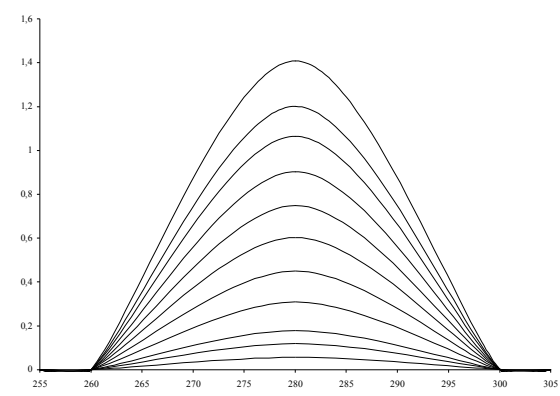

D2

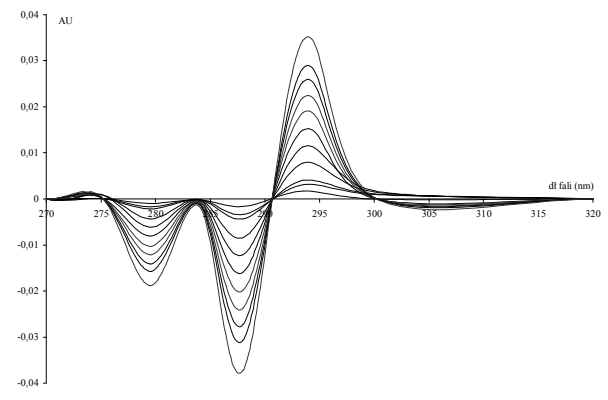

D1

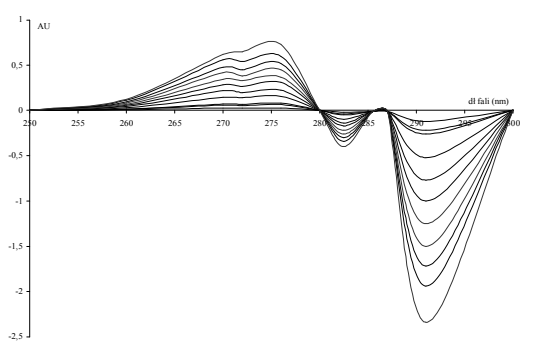

D3

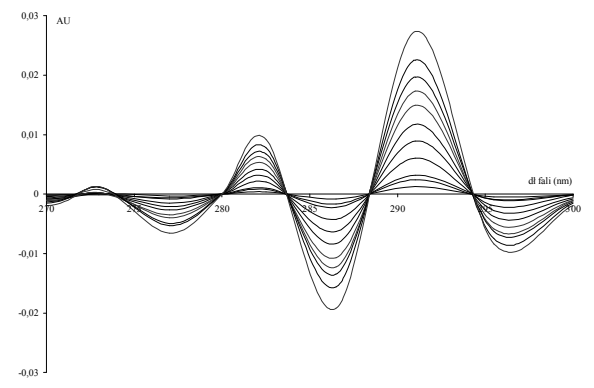

Figure 2. A - absorption spectra of $D X M H B r$ in ethanol, D1 - first order, D2 second order derivative, $D 3$ - third order derivative; spectra in the range $1.0-25.0 \mu \mathrm{g} \mathrm{ml}^{-1}$ of $\mathrm{DXM} \mathrm{HBr}$

The values obtained with an appropriate calibration graph recorded within the wavelength range $240-320 \mathrm{~nm}$, against ethanol as a blank. Presented method provided good correlation between the analytical signal analyte concentration $(\mathrm{r}=0.9999)$. Regression intercept were negligibly small and thus assigned to 0 . Mandel's fitting test was applied for the mathematical verification of linearity (variance homogeneity was tested by F-test for the highest and the lowest concentration of $D X M$ standard solutions). Detection limit of the derivative spectrophotometric method was expressed as LD $-\sigma / S$, where $S$ is the slope of the corresponding calibration curve and $\sigma$ is the standard deviation of the blank signal. Precision: in order to evaluate the repeatability, the lowest and highest concentrations within the linear range $(1.0 \mu \mathrm{g}$ $\mathrm{ml}^{-1}$ and $25 \mu \mathrm{g} \mathrm{ml}^{-1}$ respectively) were determined three times. The obtained RSD values varied from 1.86 to $0.60 \%$. The intra-day precision was also studied by repeating the analytical procedure for six samples within the same day. The inter-day precision was examined by repeating the determination of the analyte in six samples within three subsequent days. The results were evaluated with F-Snedecor test. Experimental $F$ values did not exceed theoretical ones referring to $P=95 \%$ for $n_{1}, n_{2}=6$. Thus, the results obtained during succeeding days did not differ significantly with respect 
to variability. Accuracy: the accuracy of UV spectra and derivatives investigated methods were evaluated. For this purpose one studied the recovery of dextromethorphani in tablets. The indispensable time necessary for the extraction of dextromethorphani hydrobromidum from tablets was $30 \mathrm{~min}$. The $\mathrm{DXM} \mathrm{HBr}$ content was determined for the first derivative spectra signal at the "peak - zero" points $276 \mathrm{~nm}$, $291.0 \mathrm{~nm}$ and at the "peak - peak" points $(276.0-291.0 \mathrm{~nm})$; for the second derivative spectrum by measuring the second derivative signal at the "peak- zero" points 288.0 $\mathrm{nm}, 293.5 \mathrm{~nm}$ and at the peak-peak" points $(288.0-293.5 \mathrm{~nm})$ and for the third derivative signal at the "peak-zero" points $282.5 \mathrm{~nm}, 286.5 \mathrm{~nm}, 291.0 \mathrm{~nm}$, and at the "peak-peak' points $(282.5-286.5 \mathrm{~nm}),(286.5-291.0 \mathrm{~nm})$. The procedure was repeated six times. The accuracy was studied by applying Student's $t$-test $(\mathrm{P}=95 \% ; \mathrm{n}=$ 6). Neither D1, D2, D3 methods used significant difference between the mean recovery nor $100 \%$ value appeared. Table 2 illustrates the date on the determination of $\mathrm{DXM} \mathrm{HBr}$ in the tablets with statistical evaluation of the best results.

Table 2. Statistical analysis of the results of the determination of $D X M H B r$ in tablets $A C O D I N$ by the classic UV spectra and D1, D2 and D3 order derivative UV spectrophotometric methods $(n=6)$

\begin{tabular}{|l|c|c|c|c|}
\hline Parameter & $\mathrm{A} / 280$ & $\mathrm{D} 1 /{ }_{276-291}$ & $\mathrm{D} 2 /{ }_{288-293,5}$ & $\mathrm{D} 3 / 291$ \\
\hline Mean content $\overline{\mathrm{X}}$ & 15.06700 & 15.00700 & 15.96900 & 15.97000 \\
Standard deviation S & 0.03750 & 0.04038 & 0.03195 & 0.07090 \\
Standard deviation of mean S $\bar{x}$ & 0.03424 & 0.03686 & 0.29160 & 0.06490 \\
Variance S & 0.00140 & 0.00163 & 0.00102 & 0.00502 \\
Relative standard deviation RSD & 3.20000 & 3.65000 & 3.00000 & 3.61000 \\
$(\%)$ & 1.06750 & 1.00760 & 0.96960 & 0.97020 \\
Confidence interval (95\%) & & & & \\
\hline Difference between the mean & & & & \\
recovery and 100\% ( $t$-Student test, & $\mathrm{t}=0.84$ & $\mathrm{t}=0.48$ & $\mathrm{t}=53$ & $\mathrm{t}=56$ \\
$\mathrm{P}=95 \%)$ & & & & \\
$\mathrm{t}_{\alpha, \mathrm{f}}=2.57$ & $\mathrm{~F}=4.12$ & $\mathrm{~F}=1.04$ & $\mathrm{~F}=1.42$ & $\mathrm{~F}=1.18$ \\
\hline Inter-day precision (F-Snedecor & & & \\
test, P=95\% & & & \\
$\mathrm{F}_{0.05}=5.05$ & & & & \\
\hline
\end{tabular}

\section{CONCLUSIONS}

In summary, the proposed analytical procedure based on the first-, second- and thirdorder derivative spectroscopy permits a simple rapid, sensitive and direct determination of the analysed drug. The study presents that derivative UV spectroscopy (the first, second and third derivative only) can be successfully applied for the quantitative analysis of dextromethorphani hydrobromidum both pure and in pharmaceutical 
formulations. This method can yield results in a short time and does not require relatively expensive apparatus like in, e.g., GC or HPLC.

\section{REFERENCES}

Brenner GM, Stevens CW. Pharmacology, Saunders; 2 ed., 2006.

Brunton L, Lazo J, Parker K. Goodman \& Gilman's The Pharmacological Basis of Therapeutics, McGraw-Hill Professional; 11 ed., 2005.

Galli V, Barbas C. High-performance liquid chromatographic analysis of dextromethorphan, guaifenesin and benzoate in a cough syrup for stability testing. $\mathbf{J}$ Chromatogr. 2004;1048:207-211.

Lin SY, Chen CH, Ho HO, Chen HH, Sheu MT. Simultaneous analysis of dextromethorphan and its three metabolites in human plasma using an improved HPLC method with fluorometric detection. J Chromatogr. 2007;859:141-146.

Louhaichi MR, Jebali S, Loueslati MH, Monser L. Simultaneous determination of dextromethorphan hydrobromide, pyrilamine maleate and sodium benzoate in cough cold syrup by LC. Chromatographia. 2009;69:421-427.

Louhaichi MR, Jebali S, Loueslati MH, Adhoum N, Monser L. Simultaneous determination of pseudoephedrine, pheniramine, guaifenesin, pyrilamine, chlorpheniramine and dextromethorphan in cough and cold medicines by high performance liquid chromatography. Talanta. 2009;78:991-997.

Santagati NA, Gotti R, Ronsisvalle G. Simultaneous determination of phenytoin and dextromethorphan in urine by solid-phase extraction and HPLC-DAD. Journal of Separation Science. 2005;28:1157-1162.

Lou H, Yuan H, Ruan Z, Jiang B. Simultaneous determination of paracetamol, pseudoephedrine, dextrophan and chlorpheniramine in human plasma by liquid chromatography-tandem mass spectrometry. J Chromatogr. 2010;878:682-688.

Zhang W, Han F, Guo P, Zhao H, Lin Z, Huang MQ, Bertelsen K, Weng N. Simultaneous determination of tolbutamide, omeprazole, midazolam and dextromethorphan in human plasma by LC-MS/MS-A high throughput approach to evaluate drug-drug interactions. J Chromatogr. 2010;878:1169-1177.

Bagheri H, Es-haghi A, Rouini MR. Sol-gel-based solid-phase microextraction and gas chromatography-mass spectrometry determination of dextromethorphan and dextrorphan in human plasma. J Chromatogr. 2005;818:159-167. 
Dong Y, Chen X, Chen Y, Chen X, Hu Z. Separation and determination of pseudoephedrine, dextromethorphan, diphenhydramine and chlorpheniramine in cold medicines by nonaqueous capillary electrophoresis. J Pharm Biomed Anal. 2005;39:285-289.

Yang XJ, Li OL, Chen ZG, Liu C, Lan Y, Zhao S. Determination of pseudoephedrine hydrochloride and dextromethorphan hydrobromide in cold tablet by micro-fluidic chip. Fenxi Huaxue. 2008;36:673-677.

Heli H, Majdi S, Jabbari A, Sattarahmady N, Moosavi-Movahedi AA. Electrooxidation of dextromethorphan on a carbon nanotube-carbon microparticle-ionic liquid composite: applied to determination in pharmaceutical forms. J Solid State Electrochem. 2010;14:1515-1520.

Khaled E, Hassan HNA, Mohamed GG, Seleim AA. Carbon paste and PVC electrodes for the flow injection potentiometric determination of dextromethorphan. Talanta. 2010;81:510-515.

El-Naby EH. Polymeric membrane sensors for the selective determination of dextromethorphan in pharmaceutical preparations. Anal Sci. 2008;24:1409-1414.

Sánchez RF, Bosch OC. Recent development in derivative ultraviolet/visible absorption spectrophotometry: 2004-2008: a review. Anal Chim Acta. 2009;635:22-44.

Registered: January 16, 2012

Dr. Joanna Drozd, PhD.

Accepted: July 2, 2012

Medical University of Lublin

Faculty of Pharmacy

Jaczewskiego Str. 4

20-090 Lublin

Poland

e-mail: joanna.drozd@umlub.pl

Acta Fac. Pharm. Univ. Comen. LIX, 2012, p. 22-29. 